\title{
Dietary supplements: foods, medicines, or both? A controversial designation with unspecific legislation
}

\author{
Carla Pereira ${ }^{1}$, Lillian Barros ${ }^{1,2, *}$ Isabel C.F.R. Ferreira ${ }^{1,{ }^{*}}$
}

\author{
${ }^{1}$ Centro de Investigação de Montanha (CIMO), ESA, Instituto Politécnico de Bragança, Campus de Santa \\ Apolónia, 1172, 5301-855 Bragança, Portugal \\ ${ }^{2}$ Laboratory of Separation and Reaction Engineering (LSRE) - Associate Laboratory LSRE/LCM, Faculty \\ of Engineering, University of Porto, Porto, Portugal.
}

*Author to whom correspondence should be addressed (e-mail: iferreira@ipb.pt telephone +351-273303219; fax +351-273-325405; e-mail: lillian@ipb.pt; telephone +351-273-303903; fax +351-273$325405)$.

\begin{abstract}
Background: Dietary supplements have been widely used among the United States of America (USA) and the European Union (EU) population not only as a form of nutrition but also for medicinal purposes. Still, the legislation regulating these supplements remains unclear due to the fact that they can be considered as foodstuffs and/or medicinal products depending on various factors. Methods: The present review article intendeds to provide information concerning the variations on the definition of dietary supplements, the allowable substances on it, as well as the marketing and labelling requirements among the USA and the EU legislation. Results/Conclusions: In fact, several discrepancies can be found between regulations in the USA (mainly regulated by the Food and Drugs Administration) and in the EU (principally regulated by the Food Supplements Directive or by the Directive 2001/83/EC), and even between the different Member States of the EU, with the main differences observed in new products marketing requirements.
\end{abstract}

Keywords: Dietary supplements; USA legislation; EU legislation. 


\section{Widespread use of dietary supplements}

An adequate and balanced nutrition is considered the key to maintain the normal body functions, prevent diseases, and age healthily. Nevertheless, there are several cases of malnutrition due to deficient, excessive or imbalanced intake of a wide range of nutrients present in food [1]. This lack of nutrition can derive from different origins such as medical (for instance anorexia, nausea and vomiting or gastrointestinal dysfunction) and/or environmental causes (poor food quality or availability, no respected meal times, etc.), or altered requirements (altered substrate demands in critical illness, or increased energy expenditure) [2]. For this kind of reasons, or even just to improve or maintain the overall health, wellness and mental conditions, balance the diet, perk up the appearance, boost the performance or delay the onset of age-related diseases, the application of dietary supplements has tremendously increased in the last decades $[3,4,5,6,7]$. Nowadays, these supplements are widely used as a form of nutrition not only by healthy individuals but also by patients with a variety of health issues because they tend to be perceived as natural and safe; nonetheless, the prevalent use remains in patient populations who are frequently hospitalized or at risk of hospitalization, such as users of prescription medication, patients with chronic conditions, and the elderly [8]. Among their various applications, the most common are weight loss [9,10], diabetes [11], dementia [1], cognition [12], prostatic hyperplasia [13], epilepsy [14], gastrointestinal issues [15], and sexual [16], bones, and articulations $[17,18]$ performance improvement, among others. The growing interest on dietary supplements has led to the production and commercialization of a wide range of formulations containing vitamins, minerals, herbal preparations, or similar ingredients and, consequently, has facilitated their distribution in several points with free availability like pharmacies, health food stores, department stores, groceries, on the Internet, and even on the black market [7,19]. Albeit the easy access to these products offers obvious advantages by simplifying the buying process of effective professionally counselled treatments, the fact that anyone can easily access a variety of other supplements without medical prescription or advice can have several associated risks. Indeed, negative interactions with prescribed drugs, side effects, and other adverse effects have been noted, and once complementary and alternative medicine is not currently integrated with conventional medicine, a specific legislation for dietary supplements with medicinal purposes is increasingly necessary $[20,21,22]$. 


\section{Dietary supplements on the borderline between food and medicine legislation}

It is estimated that in the USA and the EU, nearly half of the population currently uses dietary supplements and that in Europe the prevalence of consumption is localized in the northern countries [5,23]. Still, the scope and definition of these supplements remains unclear, with variations among the applied legislation among different countries.

Since ancient times, natural products such as plants and herbs have been used as healing agents, remaining the most common form of traditional medicine worldwide, and with the organic chemistry advances, the industry was able to prepare several synthetic medicines from natural sources, for instance acetylsalicylic acid [24], immunosuppressive cyclosporines [25], anthracycline antibiotics [26], or statins [27]. Nonetheless, most of these natural products can also be used in human diet, as source of nutrients and, in this perspective, dietary supplements containing this sort of constituents do not exactly fit into neither medicine nor food scope because pharmaceuticals are used to cure diseases or alleviate its symptoms, whereas foods are primarily used to prevent diseases through the supply of macro and micronutrients needed for good health in an optimal balance. Recently, the increased emergence of dietary supplements, and particularly those containing substances other that vitamins and minerals that exert both functions, on the market has blurred the distinction between pharmaceuticals and food, which place them in the borderline between food and drug legislation [6,7].

In order to provide an easier comparison between the USA and the EU legislation regarding dietary supplements, the present study was conducted by a thorough survey of the principal competent authorities' regulation documents (laws, regulations, directives, reports, etc.). For that purpose, we intended to provide a definition of dietary supplements, the allowable substances on its manufacturing, and the marketing and labelling requirements depending on the area of marketing and on the classification of such products as food or medicines.

\section{Definition of dietary supplements}

In the USA, dietary supplements are mainly regulated by the Food and Drug Administration (FDA) (Figure 1) and have always been regulated as foods, with the enacting of the basic Food, Drug and Cosmetic Act (FD\&C Act), in 1938 [7,28]. In this Act, Congress created a category of "foods for special dietary use" to include vitamin supplements, fortified foods or infant formula, which required a different label informing consumers about their special dietary properties. In 1941, the FDA proposed a new definition that was 
incorporated in Section 411 of the FD\&C Act in 1976, under which special dietary uses included many specific functions like "supplying a vitamin, mineral, or other ingredient for use by man to supplement his diet by increasing the total dietary intake" $[7,29,30]$. Later, in order to formalise a number of regulatory statutes designed to ensure continued public access to a wide variety of dietary supplements and to provide consumers with more information about the intended use of dietary supplements, Dietary Supplement Health and Education Act 1994 (DSHEA) was enacted. According to DSHEA, a dietary supplement is "a product (other than tobacco) intended to supplement the diet that bears or contains one or more of the following dietary ingredients: a vitamin, a mineral, an herb or other botanical, an amino acid, a dietary substance for use by man to supplement the diet by increasing the total dietary intake, or a concentrate, metabolite, constituent, extract, or combination of any of the aforementioned ingredients; it is deemed to be food, except for purposes of the drug definition". However, despite the modifications introduced by this Act, it did not change the fact that dietary supplements are classified as a category of foods [7,31]. Thus, hitherto the definition of this kind of supplements was considered by the Congress for three distinct occasions: in 1938, in 1976, and in 1994, and on each one the conclusion was that they were a subset of foods. Notwithstanding, the scope of these supplements have been submitted to these reviews due to the fact that some of these products could be considered drugs if their labelling suggested that they could be used for "diagnosis, cure, mitigation, treatment, or prevention of disease", which is how drugs are defined in Section $201(\mathrm{~g})$ of the FD\&C Act [7,32].

On the other hand, in the EU (Figure 2), the European Food Safety Authority (EFSA) was set up in January 2002 as an independent source of scientific advice that produces opinions to be used by the European Commission (EC) that adopt legislation concerning dietary supplements; EFSA works, then, in close collaboration with national authorities and in open consultation with its stakeholders [7,33]. Moreover, and with special relevance for companies in this sector, EFSA contributed in the evaluation of proposals for the addition of vitamins and minerals to the Food Supplements Directive (FSD), Directive 2002/46/EC, which states that food supplements are "foodstuffs the purpose of which is to supplement the normal diet and which are concentrated sources of nutrients or other substances with a nutritional or physiological function, alone or in combination, marketed in dose form, namely forms such as capsules, pastilles, tablets, pills and other similar forms, sachets of powder, ampoules of liquids, drop dispensing bottles, and other similar forms of liquids and powders designed to be taken in measured small unit quantities" [7,34]. Dietary supplements containing herbal medicinal products are regulated by the Directive 2001/83/EC, which regulates the 
medicinal products for human use and by the Traditional Herbal Medicinal Products (THMP) Directive 2004/24/EC that emerged to amend Directive 2001/83/EC regarding to the marketing of THMP on the EU. The Directive 2001/83/EC provides legal definitions for herbal medicinal products, herbal substances, and herbal preparations. Accordingly, a herbal medicinal product is "any medicinal product, exclusively containing as active ingredients one or more herbal substances or one or more herbal preparations, or one or more such herbal substances in combination with one or more such herbal preparations"; on the other hand, herbal substances are "all mainly whole, fragmented or cut plants, plant parts, algae, fungi, lichen in an unprocessed, usually dried form, but sometimes fresh, and also certain exudates that have not been subjected to a specific treatment"; while herbal preparations are "preparations obtained by subjecting herbal substances to treatments such as extraction, distillation, expression, fractionation, purification, concentration or fermentation" that include "comminuted or powdered herbal substances, tinctures, extracts, essential oils, expressed juices and processed exudates" [6,7,28,35].

\section{Marketing requirements for dietary supplements}

In the USA, according to DSHEA, dietary supplements are considered as a category of food, which put them under different regulations than drugs. As such, they must be labelled as food and "be intended for ingestion, they must not be represented for use as conventional food or as a sole item of a meal or of the diet and cannot be approved or authorized for investigation as new drugs, antibiotics, or biologics, unless they were marketed as food or dietary supplements before such approval or authorisation" [7,31]. The Office of Nutritional Products, Labelling, and Dietary Supplements is the principal office responsible for regulation of these products at the FDA, that regulates the marketing of dietary supplements and, therefore, can either refuse to allow new ingredients into or remove existing ingredients from the market for safety reasons [7]. Nevertheless, FDA's authority to monitor structure/function claims of dietary supplements remains limited by law and has, currently, three main requirements to help ensure that such claims are truthful and not misleading: "substantiation to support the claims, which manufacturers must possess but need not submit to FDA; notification to FDA of claims within 30 days of first marketing the supplement with the claim; and a required disclaimer on supplement labels" [7,36]. Although manufacturers are not required to perform clinical trials to test new ingredients or supplements, FDA can stop a company from marketing a dietary supplement if proven that the product is ineffective or unsafe. In order to ensure the quality of supplements, the conditions of preparation, packaging, and storage are issued by FDA through 
Good Manufacturing Practices regulations, which are primarily concerned with safety and sanitation rather than quality [7,37]. The fact that DSHEA does not impose safety testing or approval of dietary supplements result in a lack of information to FDA that do not possess a comprehensive list of dietary supplements on the market; still, manufacturers must ensure that their products are safe, that they can, by evidence, substantiate structure/function claims, and that product labels are truthful and not misleading. To ensure the safety of supplements marketed in the USA, FDA monitors adverse event reports and consumer complaints, search in the Internet for products that are not in agreement with regulations, conduct onsite inspections of manufacturers' facilities or imported shipments, and reviews new dietary ingredient notifications. This authority do not survey dietary supplements sold on retail establishments but it does conduct limited surveillance of products sold on the Internet [7,31,38] (Figure 3).

In the EU, according to FSD, the fact that dietary supplements are subjected to different regulations in the various Member States "may impede their free movement, create unequal conditions of competition, and thus have a direct impact on the functioning of the internal market", which explains the need to "adopt Community rules on those products marketed as foodstuffs" [7,34]. Anyway, a high level of protection for consumers and a facilitated choice must be ensured by putting on to the market safe products that bear adequate and appropriate labelling [7,34]. Additional requirements to ensure the quality of medicinal products can be found in Directive 2003/63/EC, which amends Directive 2001/83/EC. This Directive contains details of the scientific and technical requirements regarding to the marketing authorisation application dossier. Importantly, the unique aspects of herbal medicinal products quality are acknowledged in the preamble of this Directive that states that "herbal medicinal products differ substantially from conventional medicinal products in so far as they are intrinsically associated with the very particular notion of herbal substances and herbal preparations" and also refers that "it is therefore appropriate to determine specific requirements in respect of these products with regard to the standardised marketing authorisation requirements" [6,7,40]. In 2004, the Directive 2004/24/EC attempted to (i) facilitate the registration of certain traditional herbal medicinal products, suggesting that "there should be the possibility of establishing a Community list of herbal substances that fulfill certain criteria, such as having been in medicinal use for a sufficiently long time, and hence are considered not to be harmful under normal conditions of use"; and (ii) enhance harmonisation, proposing that "Member States should recognise registrations of traditional herbal medicinal products granted by another Member State based on Community herbal monographs or consisting of substances, preparations or combinations thereof contained in a list to be established", and 
with respect to other products "Member States should take due account of such registrations" [7,41]. Thus, in the amended Directive 2001/83/EC, a simplified registration procedure is established for these supplements which fulfill criteria such as (i) having indications exclusively appropriate to THMP, being intended and designed for use without the supervision of a medical practitioner for diagnostic purposes or for prescription or monitoring of treatment; (ii) being exclusively for administration in accordance with a specified strength and posology; (iii) being an oral, external an/or inhalation preparation; (iv) having been in medicinal use throughout a period of at least 30 years preceding the date of the application, including at least 15 years within the Community; and (v) proving to not be harmful in the specified conditions of use, with pharmacological effects or efficacy plausible on the basis of long-standing use and experience. Moreover, the amended Directive states that the applicant and registration holder shall be established in the Community and submit an application to the competent authority of the concerned Member State in order to obtain traditional-use registration [7,41]. Nevertheless, the fact that the European Medicines Agency does not have a role in the registration of THMP means that applications for registration have to be submitted in each Member State where the product is to be marketed and are handled by the respective competent authority. In this context, the Court of Justice has concluded on several occasions that the differences between the classification of products as foodstuffs or medicinal products in the different Member States will persist as long as there is no more complete harmonization of the measures required to ensure health protection. Thus, a product classified as foodstuff in another Member State can, at the same time, be marketed as medicinal product in the importation Member State, if it shows the characteristics of such a product. In cases where a product fulfills the definition of food supplement (as laid down in FSD) but, simultaneously falls within one of the definitions of medicinal product (contained in the Directive 2001/83/EC), the provisions of the legislation applicable to medicinal products shall apply [7,39]. When it regards to medicinal products, the Member States competent authorities grant marketing authorisations for medicinal products placed on their markets, except for medicinal products which are authorized under Regulation (EC) 726/2004. In cases where national authorisations in more than one Member State are required for the same medicinal product and the marketing authorisation holder has obtained a marketing authorisation in a Member State, this latest must submit an application in the concerned Member State using the procedure of mutual recognition. Then, the concerned Member States should recognize the marketing authorisation already granted by the reference Member State and, therefore, authorize the marketing of the product on their national territory. On the contrary, if there is no marketing authorisation in the Union for 
a given medicinal product, the applicant can submit an application in all the Member States where it intends to obtain a marketing authorisation at the same time, making use of a decentralised procedure, and choose one of them as reference Member State. The marketing authorisation should then be granted in agreement with the decision taken by the reference Member State and the concerned Member State taking into account the assessment report prepared by the reference Member State and any comments made by the concerned Member State. In order to obtain a Union authorisation, an application must be submitted to the European Medicines Agency (EMA) and its scientific evaluation is carried out within the Committee for Medicinal Products for Human Use of the EMA; a scientific opinion is then prepared and sent to the European Commission which drafts a Decision. This Decision is adopted by the Commission after consulting the Member States through the relevant Standing Committee, and the authorisation is granted. In any cases, the marketing authorisation must contain the summary of product characteristics in accordance to Article 11 of Directive 2001/83/EC [7,34]. With the exception of the products having different therapeutic indications in national (decentralised/mutual recognition) and central marketing authorisations, the co-existence of both provided by the Communication is not allowed. Indeed, if the product falls under the optional scope of the centralised procedure (Article 3(2) of Regulation (EC) 726/2004), there is a possibility of choice of using either centralised or national procedure for the same product, but it does not allow the simultaneous coexistence of both marketing authorizations. Thus, if a central marketing authorization has been issued, there is no place for an additional scientific evaluation and regulation decision for the same product. According to Directive 2001/83/EC, "any additional strengths, pharmaceutical forms, administration routes, presentations, as well as any variations and extensions" shall also be granted an authorization or be included in the initial marketing authorisation and all of these authorisations shall be considered as belonging to the same global marketing authorisation.

On the contrary, dietary supplements considered as foodstuffs should comply with FSD and Regulation (EC) 1924/2006 on nutrition and health claims made on foods because they do not fulfill the definition of medicinal products but they comply with applicable food law. In this perspective, Member States shall ensure that food supplements only may be marketed within the Community if they comply with the rules laid down in the FSD. In agreement with this Directive, only vitamins and minerals listed in Annex I, in the forms listed in Annex II, may be used to manufacture food supplements, and the purity criteria for these substances shall be adopted by the Commission. Apart from the vitamins and minerals listed in Annex I or forms listed in Annex II, Member States may allow in their territory the use of such substances, provided 
that it "is used in one or more food supplements marketed in the Community on the date of entry into force of this Directive" or the EFSA "has not given an unfavorable opinion in respect of the use of that substance, or its use in that form, in the manufacture of food supplements, on the basis of a dossier supporting use of the substance in question to be submitted to the Commission by the Member State" [7,34]. Since May 2011, all unlicensed herbal medicinal products must either be marketed as medicines, or they must be removed from the market. They could be launched correctly labelled as food supplements, carrying no claims unless they have been approved according to the Nutrition and Health Claims Regulation. However, the classification of some dietary supplements as food products has raised some concerns due to the fact that the food law is not regulated as strictly as the drug law which contains additional regulatory provisions for protection of the consumer's health; and also because it is necessary to disclose the factual therapeutic properties of medicinal plants in form of disease related indications and not in form of masked healthrelated claims [7,42] (Figure 3).

\section{Allowable substances on dietary supplements}

In the USA, with the passage of DSHEA, a new law requiring pre-market safety notification for new dietary supplements ingredients became necessary and, this pre-market concept comprises two different categories: ingredients in the market before October 15, 1994, which are considered old dietary ingredients and presumed to be safe; and ingredients marketed after October 15, 1994 that are considered new dietary ingredients and, thus, require FDA pre-market review of safety [7,31]. In a general way, a dietary supplement is considered safe until proven unsafe, and as can be read in FD\&C Act, amended by DSHEA, a dietary supplement or ingredient is considered unsafe if (i) it "presents a significant or unreasonable risk of illness or injury under conditions of use recommended or suggested in labelling, or if no conditions of use are suggested or recommended in the labelling, under ordinary conditions of use"; (ii) it "is a new dietary ingredient for which there is inadequate information to provide reasonable assurance that such ingredient does not present a significant or unreasonable risk of illness or injury; (iii) "the Secretary declares to pose an imminent hazard to public health or safety, except that the authority to make such declaration shall not be delegated and the Secretary shall promptly after such a declaration initiate a proceeding in accordance with sections 554 and 556 of title 5 to affirm or withdraw the declaration; or (iv) it "is or contains a dietary ingredient that renders it adulterated under the conditions of use recommended or suggested in the labelling of such dietary supplement". If a dietary ingredient is considered safe by 
respecting the referred requirements, it can thus be introduced in dietary supplements to be marketed $[7,31,38]$.

In the EU, specific rules on vitamins and minerals in food supplements were introduced by the FSD; Annex II is a list of permitted vitamin or mineral preparations that may be added for specific nutritional purposes in food supplements. In order to include additional substances, it has latter been amended by the Commission Directive 2006/37/EC, the Commission Regulation (EC) 1170/2009, the Commission Regulation (EU) 1161/2011, the Commission Regulation (EU) 119/2014 and the Commission Regulation (EU) 2015/414. The trade of products containing vitamins and minerals not listed in Annex II has been prohibited from the 1st of August 2005 [7,43]. Although FSD calls for establishment of harmonized minimum and maximum dosage amounts through the Standing Committee procedures and lays down the criteria for their setting, this has yet to be done and remains a competence of EU Member States that are also responsible for the rules regulating substances other than vitamins and mineral, once they are not directly covered by the FSD. With this concern, the EFSA and the Scientific Committee of Food were requested by the EC to provide scientific opinions on assessing how to establish maximum levels of vitamins and mineral permitted in food supplements, as also additional opinions on nutrients other than these substances. Among these other substances are amino acids, enzymes, pre- and probiotics, essential fatty acids, botanicals and botanical extracts, and miscellaneous bioactive substances [7,34,43]. In June 2006, the Directorate General Health and Consumer Protection has published a discussion paper on the establishment of maximum and minimum amounts of vitamins and minerals in foods where the issues to be considered in this exercise are identified; furthermore, all interested parties were invited to provide their view, which are currently in analysis [7,44].

Regarding to dietary supplements considered as medicinal products, including herbal medicinal products, a Committee for Herbal Medicinal Products, established at the EMA was created to establish Community monographs for THMP and further facilitate the registration and harmonization in this field. A draft list was then prepared taking into account the substances used in traditional medicine for a sufficiently long time to be considered safe under normal conditions of use. The referred list is present on the Commission Decision 2008/91/EC that was, latter, amended in order to include new substances, by several Commission Decisions $[7,45]$. 


\section{Labelling of dietary supplements}

According to the FD\&C Act and the respective amendments by DSHEA, in the USA, dietary supplements must carry on the label the name and the quantity of each ingredient or with respect to a proprietary blend of such ingredients, the total quantity of all ingredients in the blend. The label must also identify the product by using the term "dietary supplement", which may be modified with the name of such an ingredient and, in cases where the supplement contains plants material, the labelling must identify the parts of the plant from which it was derived. Regarding to supplement listing on the nutrition labelling, a dietary supplement shall comply with some labelling requirements such as first listing the dietary ingredients that are present in the product in a significant amount and for which a recommendation for daily consumption has been established by the Secretary, and also list any other dietary ingredient present and identified as having no such recommendation. The listing if dietary ingredients shall include the quantity of each ingredient per serving and may include the source of the ingredient; the nutrition information shall immediately precede the ingredient information, except that no ingredient identified shall be required to be identified a second time. Moreover, the label of a dietary supplement or food product may contain one of three types of claims: health claim, nutrient content claim, or structure/function claim. Nonetheless, the claims may not explicitly or implicitly claim to prevent, treat, mitigate, cure, or diagnose a disease; it can claim a benefit related to a classical nutrient deficiency disease with disclosed prevalence in the US, characterize the documented mechanism by which a nutrient or dietary ingredient acts in the maintenance of such structure or function, or describe well-being from consumption of a nutrient or dietary ingredient. In cases where this is not respected and a dietary supplement label contain a disease claim, FDA treats the product as an unapproved drug and may take enforcement actions against the manufacturer or distributor. Among these actions, FDA can issue a warning letter, seize the product, seek criminal prosecution, or prohibit the sale of the product through an injunction $[7,31,38]$ (Figure 4).

In the EU, the labelling and the package leaflet of dietary supplements considered as medicinal products must respect Title V of the Directive 2001/83/EC. Accordingly, some particulars shall appear on the outer packaging or, where it does not apply, on the immediate packaging, such as "the name of the medicinal product followed by its strength and pharmaceutical form, and, if appropriate, whether it is intended for babies, children or adults"; "a statement of the active substances expressed qualitatively and quantitatively per dosage unit or according to the form of administration for a given volume or weight, using their common names"; "the pharmaceutical form and the contents by weight, by volume or by number of doses of the 
product"; "a list of those excipients known to have a recognized action or effect"; "the method of administration and, if necessary, the route of administration"; "a special warning that the medicinal product must be stored out of the reach and sight of children"; "a special warning, if this is necessary for the medicinal product"; "the expiry date in clear terms (month/year)"; "special storage precautions, if any"; among many others. The Directive also contains recommendations on the labelling of products subject and not subject to prescription, stating that the National competent authorities must notify the Commission of non-prescription medicinal products which they judge to be at risk of falsification and may inform the Commission of medicinal products which they deem not to be at risk according to criteria also described in the Directive, and specifies how the Member States may proceed regarding to reimbursement purposes (Article 54a) [7,35].

The labelling requirements applied to dietary supplements considered as foodstuffs are described in the FSD, in accordance with the Article 5(1) of Directive 2000/13/EC, relating to the labelling, presentation and advertising of foodstuffs, whereby the name under which products covered by this Directive are sold shall be "food supplement". Moreover, these supplements must not carry on the label, presentation and advertising the property of preventing, treating or curing a human disease, but should carry some particulars such as (i) "the names of the categories of nutrients or substances that characterize the product or an indication of the nature of those nutrients or substances";

(ii) "the portion of the product recommended for daily consumption"; (iii) "a warning not to exceed the stated recommended daily dose"; (iv) "a statement to the effect that food supplements should not be used as a substitute for a varied diet"; and (v) "a statement to the effect that the products should be stored out of the reach of young children". Also, the label should not present any mention stating or implying that the appropriate quantities of nutrients cannot be provided by a balanced and varied diet, and the amount of those nutrients or substances with nutritional or physiological effect shall be declared in numerical form (expressed in the units specified in Annex II to FSD), per portion of the product as recommended for daily consumption. For vitamins and minerals, the amounts shall also be indicated in percentage of the reference values mentioned in the Annex to Directive 90/496/EEC, which may also be given in graphical form. In order to facilitate the efficient monitoring of food supplements, the person placing the product on the market may be required (by the Member State in which the product is placed on the market) to forward a model of the label used for the product to the competent authority $[6,7,34,46,47]$. Later, the general principles of this directive were complemented by the Regulation (EC) 1924/2006 that lay down specific provisions 
concerning the use of nutrition and health claims regarding foods to be delivered as such to the consumer $[7,48]$ (Figure 4).

\section{Conclusion}

Dietary supplements are worldwide used for several purposes and its consumption is steeply increasing. Nevertheless, the safety and efficacy of such products can be compromised by the lack of specific regulatory legislation surrounding this subject. Indeed, there are many differences between the USA and EU legislation concerning dietary supplements and even among the different Member States of the EU, discrepancies can be found when it concerns the marketing of new products. In a general way, in the US, dietary supplements are considered as a food category and, therefore, are mainly regulated by the FDA that surveys their marketing and labelling requirements, through surveillance of products adverse events reports, regulations complying, and new dietary ingredients notifications, among others. On the other hand, considering that in the EU some dietary supplements fall into the scope of food and drug definition, they are often regulated as foodstuff or medicines depending on its composition, presentation, and function; thus, dietary supplements are principally regulated by the FSD or by the Directive 2001/83/EC (in accordance with the respective amendments), as appropriate. Nonetheless, according to the referred legislation, there are several improvements that need to be done because hitherto the attention has been mainly directed to food safety and claims of efficacy, but the remaining issues have been poorly explored. Further research could comprise relevant issues such as beneficial and harmful effects of the combined use of dietary supplements and chemical drugs, given that self-medication is also increasing and can result in undesirable consequences. Also, the competent authorities could explore the long-term safety of these products after being placed on the market, by assessing post-launch effectiveness and safety. To improve the correct utilization of dietary supplements, health technology assessment could be used on providing evidence about the most favourable supplements for each kind of treatment, elucidating the consumer about the cost-effectiveness and riskbenefit ratio.

\section{Conflict of interest}

The authors declare no conflict of interest. 


\section{Acknowledgments}

The authors thank the Foundation for Science and Technology (FCT, Portugal) and FEDER under Program PT2020 for financial support to CIMO (UID/AGR/00690/2013) and L. Barros (SFRH/BPD/107855/2015) grant. To POCI-01-0145-FEDER-006984 (LA LSRE-LCM), funded by FEDER, through POCICOMPETE2020 and FCT

\section{References}

[1] Allen VJ, Methven L, Gosney MA. Use of nutritional complete supplements in older adults with dementia: Systematic review and meta-analysis of clinical outcomes. Clin Nutr 2013; 32: 950-57.

[2] Saunders J, Smith T, Stroud M. Malnutrition and undernutrition. Medicine 2011; 39 (1): 45-50.

[3] Reay JL, Kennedy DO, Scholey AB. Single doses of Panax ginseng (G115) reduce blood glucose levels and improve cognitive performance during sustained mental activity. J Psychopharmacol 2005; 19: 357-65.

[4] Nichter M, Thompson JJ. For my wellness, not just my illness: North Americans' use of dietary supplements. Cult Med Psychiatry 2006; 30: 175-222.

[5] Bailey RL, Gahche JJ, Miller PE, Thomas PR, Dwyer JT. Why US adults use dietary supplements. JAMA Intern Med 2013; 173: 355-61.

[6] Regulation of herbal and traditional medicinal products - European and global strategies (International Symposium TradReg2013). The legal framework governing the quality of (traditional) herbal medicinal products in the European Union. J Ethnopharm, 2014; 158 Part B: 449-453

[7] Cross-border Life Sciences Handbook 2011 - Romania: Q\&A. Published in "Practical Law Company (PLC) Cross-border Life Sciences Handbook”, 2011

[8] Gardiner P, Graham RE, Legedza AT, Eisenberg DM, Phillips RS. Factors associated with dietary supplement use among prescription medication users. Arch Intern Med 2006; 166: 1968-74.

[9] Chang YY, Chiou WB. The liberating effect of weight loss supplements on dietary control: A field experiment. Nutrition 2014; 30: 1007-10.

[10] Gambero A, Ribeiro ML. The positive effects of yerba maté (Ilex paraguariensis) in obesity. Nutrients 2015; 7: 730-50. 
[11] González-Ortiz M, Martínez-Abundis E, Robles-Cervantes JA, Pérez-Rubio KG. Comparison of two liquid nutritional supplements designed for patients with diabetes: Effect on glucose and insulin metabolism in healthy subjects. Pharma Nutrition 2015; 3: 7-10.

[12] Clement YN, Onakpoya I, Hung SK, Ernst E. Effects of herbal and dietary supplements on cognition in menopause: A systematic review. Maturitas 2011; 68: 256-63.

[13] Kim TH, Lim HJ, Kim MS, Lee MS. Dietary supplements for benign prostatic hyperplasia: An overview of systematic reviews. Maturitas 2012; 73: 180-85.

[14] Lee SW, Chung SS. A review of the effects of vitamins and other dietary supplements on seizure activity. Epilepsy \& Behavior 2010; 18: 139-50.

[15] Lino S, Marshak HH, Herring RP, Belliard JC, Hilliard C, Campbell D, Montgomery S. Using the theory of planned behavior to explore attitudes and beliefs about dietary supplements among HIVpositive Black women. Complement Ther Med 2014; 22: 400-8.

[16] Balayssac S, Gilard V, Zedde C, Martino R, Malet-Martino M. Analysis of herbal dietary supplements for sexual performance enhancement: First characterization of propoxyphenylthiohydroxyhomosildenafil and identification of sildenafil, thiosildenafil, phentolamine and tetrahydropalmatine as adulterants. J Pharm Biomed Anal 2012; 63: 135-50.

[17] Challoumas D, Stavrou A, Pericleous A, Dimitrakakis G. Effects of combined vitamin D - calcium supplements on the cardiovascular system: Should we be cautious? Artheroclerosis 2015; 238: 388-98.

[18] LeBoff MS, Yue AY, Copeland T, Cook NR, Buring JE, Manson JE. Vital-bone health: Rationale and design of two ancillary studies evaluating the effects of vitamin D and/or omega-3 fatty acid supplements on incident fractures and bone health outcomes in the vitamin D and Omega-3 trial (vital). Contemporary Clinical Trials 2015; http://dx.doi.org/10.1016/j.cct.2015.01.007

[19] Radimer K, Bindewald B, Hughes J, Ervin B, Swanson C, Picciano MF. Dietary supplements use by US adults: data from the national health and nutrition examination survey 1999-2000. Am J Epidemiol 2004; 160: 339-49.

[20] Eisenberg DM, Kessler RC, Foster C, Nerlock FE, Calkins DR, Delbanco TL. Unconventional medicine in the United States, prevalence, costs, and patterns of use. N Engl J Med 1993; 328: 246-52. 
[21] Izzo AA, Ernst E. Interactions between herbal medicines and prescribed drugs, a systematic review. Drugs 2001; 61: 2163-75.

[22] Wallace J, Paauw DS. Appropriate prescribing and important drug interactions in older adults. Medical Clinics of North America 2015; 99: 295-310.

[23] Skeie G, Braaten T, Hjartåker A, Lentjes M, Amiano P, Jakszyn P, Pala V, Palanca A, Niekerk EM, Verhagen H, Avloniti K, Psaltopoulou T, Niravong M, Touvier M, Nimptsch K, Haubrock J, Walker L, Spencer EA, Roswall N, Olsen A, Wallström P, Nilsson S, Casagrande C, Deharveng G, Hellström V, Boutron-Ruault MC, Tjønneland A, Joensen AM, Clavel-Chapelon F, Trichopoulou A, Martinez C, Rodríguez L, Frasca G, Sacerdote C, Peeters PHM, Linseisen J, Schienkiewitz A, Welch AA, Manjer J, Ferrari P, Riboli E, Bingham S, Engeset D, Lund E, Slimani N. Use of dietary supplements in the European Prospective Investigation into Cancer and Nutrition calibration study. Eur J Clin Nutr 2009; 63: S226-38.

[24] Mahdi JG, Mahdi, AJ, Mahdi AJ, Bowen ID. The historical analysis of aspirin discovery, its relation to the willow tree and antiproliferative and anticancer potential. Cell Proliferation 2006; 39: 14755.

[25] Borel JF, Di Padova F, Mason J, Quesniaux V, Ryffel B, Wenger R. Pharmacology of cyclosporine (sandimmune). I. Introduction. Pharmacol Reviews 1990; 41: 239-42.

[26] Nadas J, Sun D. Anthracyclines as effective anticancer drugs. Expert Opin Drug Discov 2006; 1: 54968.

[27] Endo A. The origin of the statins. Atheroscler Suppl 2004; 5: 125-30.

[28] Liu Y, Wang Z, Zhang J. Dietary Chinese Herbs: Chemistry, Pharmacology and Clinical Evidence, Springer, 2015.

[29] Food and Drug Administration, 1941. Definition of "special dietary uses" and label regulations for food represented for special dietary uses. Fed Regist November 22 1941; 6:5921.

[30] Public Law 94-278, Title V, sections 501-502, 90 Stat. 410-413; April 22, 1976. [The vitamin bill, adding a new Section 411 to the FD\&C Act.]

[31] Dietary Supplement Health and Education Act of 1994. Public Law 103-417, 108 Stat. 4325-4335; October 251994. 
www.fda.gov/RegulatoryInformation/Legislation/FederalFoodDrugandCosmeticActFDCAct/def ault.htm (updated as of 3/5/2010).

[33] European Food Safety Authority. http://www.efsa.europa.eu/

[34] Directive 2002/46/EC, 2002. Directive 2002/46/EC of the European Parliament and of the Council of 10 June 2002 on the approximation of the laws of the Member States relating to food supplements. Official Journal L 183, 51-57 (12.07.2002).

[35] Directive 2001/83/EC, 2001. Directive 2001/83/EC of the European Parliament and of the Council of 6 November 2001 on the Community code relating to medicinal products for human use. Official Journal L 311, 67-128 (28.11.2001).

[36] OEI-01-11-00210, 2012. Dietary supplements: structure/function claims fail to meet federal requirements. Department of Health and Human Services, Office of Inspector General.

[37] Rapaka RS, Coates PM. Dietary supplements and related products: A brief summary. Life Sciences 2006; 78: 2026-32.

Food, Drug and Cosmetic Act ("FDA Act").
http://uscode.house.gov/view.xhtml?path=/prelim@title21/chapter9/subchapter4\&edition=prelim

[39] Commission of the European Communities, 2008. Report from the commission to the council and the European Parliament on the use of substances other than vitamins and minerals in food supplements. Brussels 5.12.2008 COM(2008) 824 final.

[40] Directive 2003/63/EC, 2003. Comission directive 2003/63/EC of the European Parliament and of the Council of 31 March 2004 amending, as regards traditional herbal medicinal products, Directive 2001/83/EC on the Community code relating to medicinal products for human use. Official Journal L 136, 85-90 (30.04.2004).

[41] Directive 2004/24/EC, 2004. Directive 2004/24/EC of 25 June 2003 amending Directive 2001/83/EC of the European Parliament and of the Council on the Community code relating to medicinal products for human use. Official Journal L 159, $46-94$ (12.07.2002).

[42] Quintus C, Schweim HG. European regulation of herbal medicinal products on the border area to the food sector. Phytomedicine 2012; 19: 378-81.

[43] http://ec.europa.eu/food/food/labellingnutrition/supplements/index_en.htm 
[44] Directorate E, Safety of the food chain, 2006. Discussion paper on the setting of maximum and minimum amounts for vitamins and minerals in foodstuffs. European Comission, Health \& Consumer Protection Directorate-General.

[45] Commission Directive 2008/91/EC, 2008. Commission Directive 2008/91/EC of 29 September 2008 amending Council Directive 91/414/EEC to include diuron as active substance. Official Journal of the European Union L 262, 31-33 (1.10.2008).

[46] Directive 90/496/EEC, 1990. Council directive 90/496/EEC of the European Communities and of the Council of 24 September 1990 on nutrition labelling for foodstuffs. Official Journal L 276, 40-44 (6.10.1990).

[47] Directive 2000/13/EC, 2000. Directive 2000/13/EC of the European Parliament and of the Council of 20 March 2000 on the approximation of the laws of the Member States relating to the labelling, presentation and advertising of foodstuffs. Official Journal of the European Communities L 109, $29-42(6.5 .2000)$

[48] Regulation (EC) No 1924/2006, 2006. Regulation (EC) No 1924/2006 of the European parliament and of the council of 20 December 2006 on nutrition and health claims made on foods. Official Journal of the European Union L 404, 9-25 (30.12.2006). 


\section{In the United States of America}

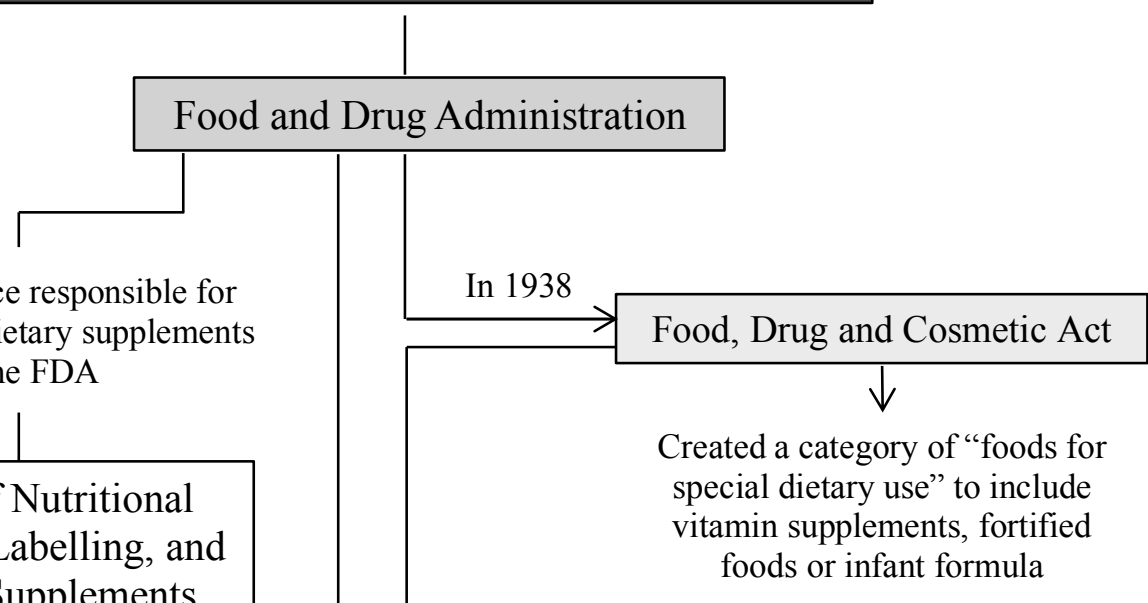

Principal office responsible for regulation of dietary supplements at the FDA

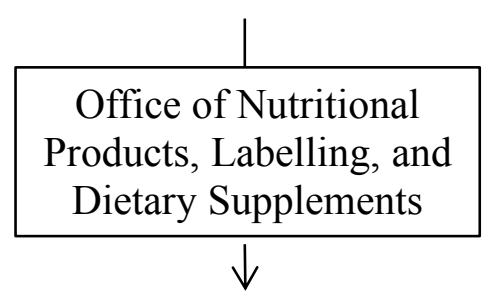

Responsible for the promotion of scientific studies performed on dietary supplements

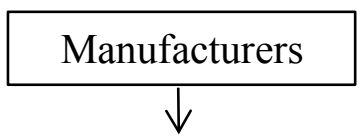

Responsible to ensure that their products are safe and that product labels are truthful and not misleading

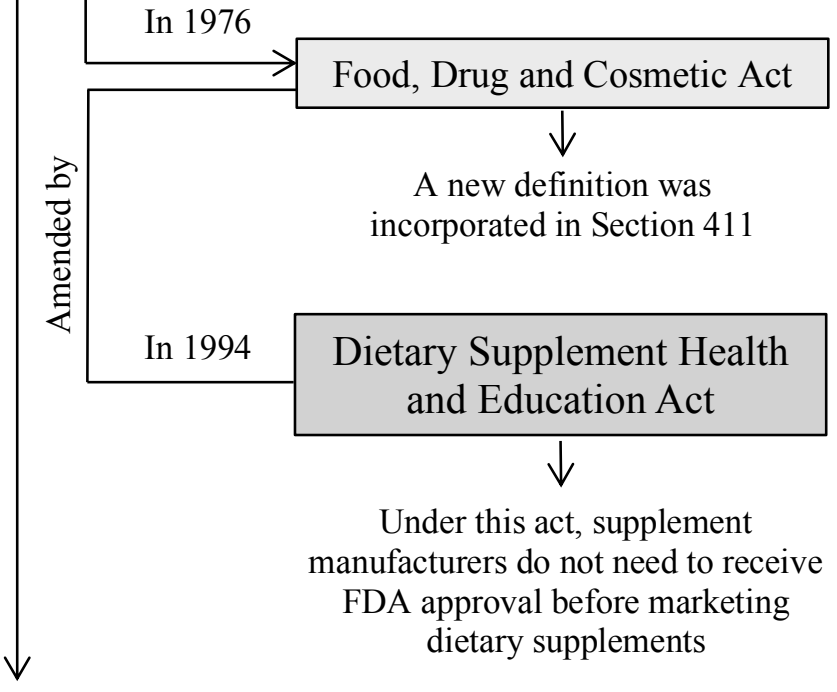

Responsible of:

- Monitoring the adverse event reports and consumer complaints;

- Searching on the Internet for products that do not comply with regulations;

- Conducting onsite inspections of manufacturers' facilities or imported shipments;

- $\quad$ Reviewing new dietary ingredient notifications.

Figure 1. Overview of the legislation on dietary supplements in the USA. 


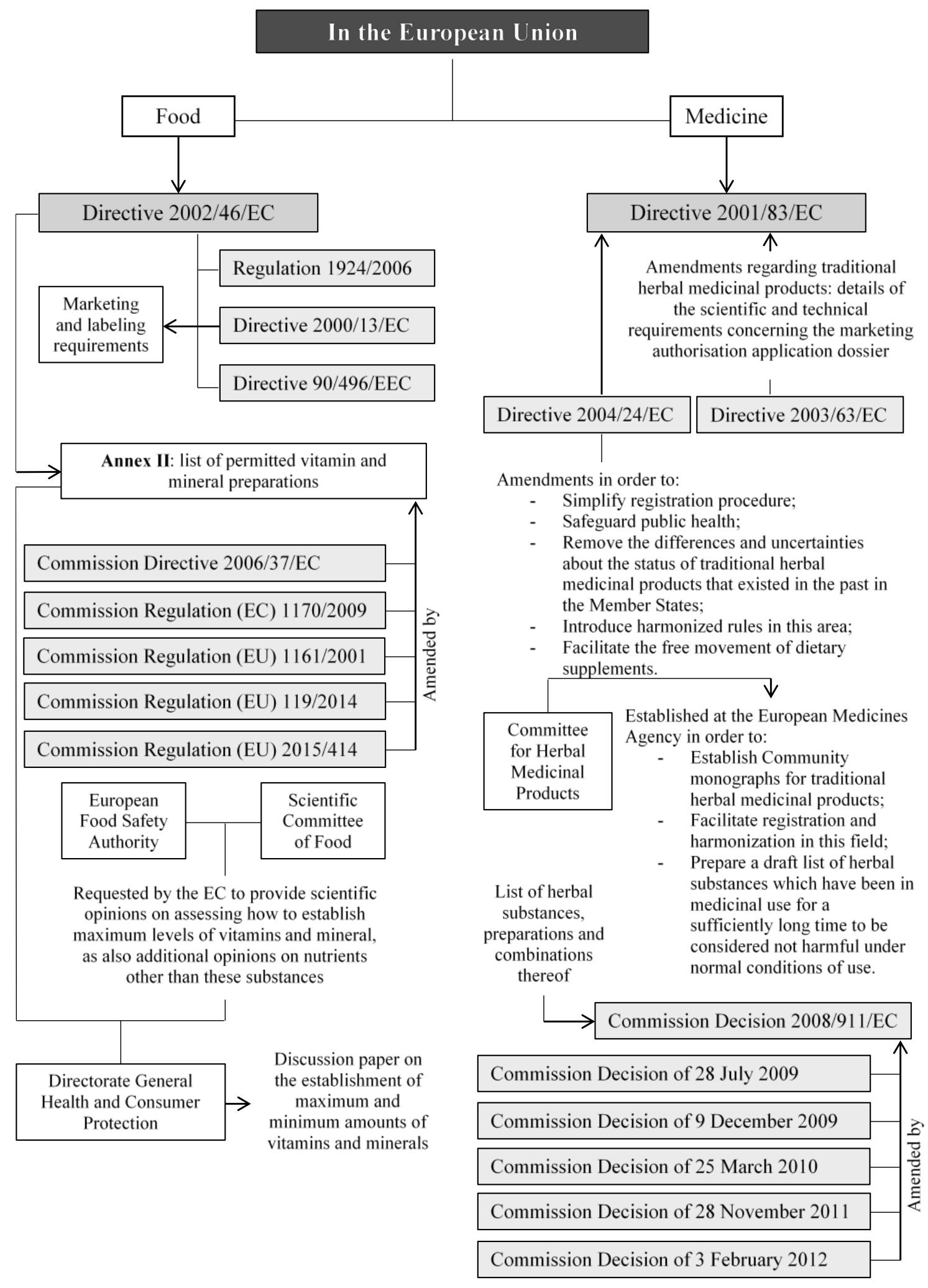

Figure 2. Overview of the legislation on dietary supplements in the EU. 


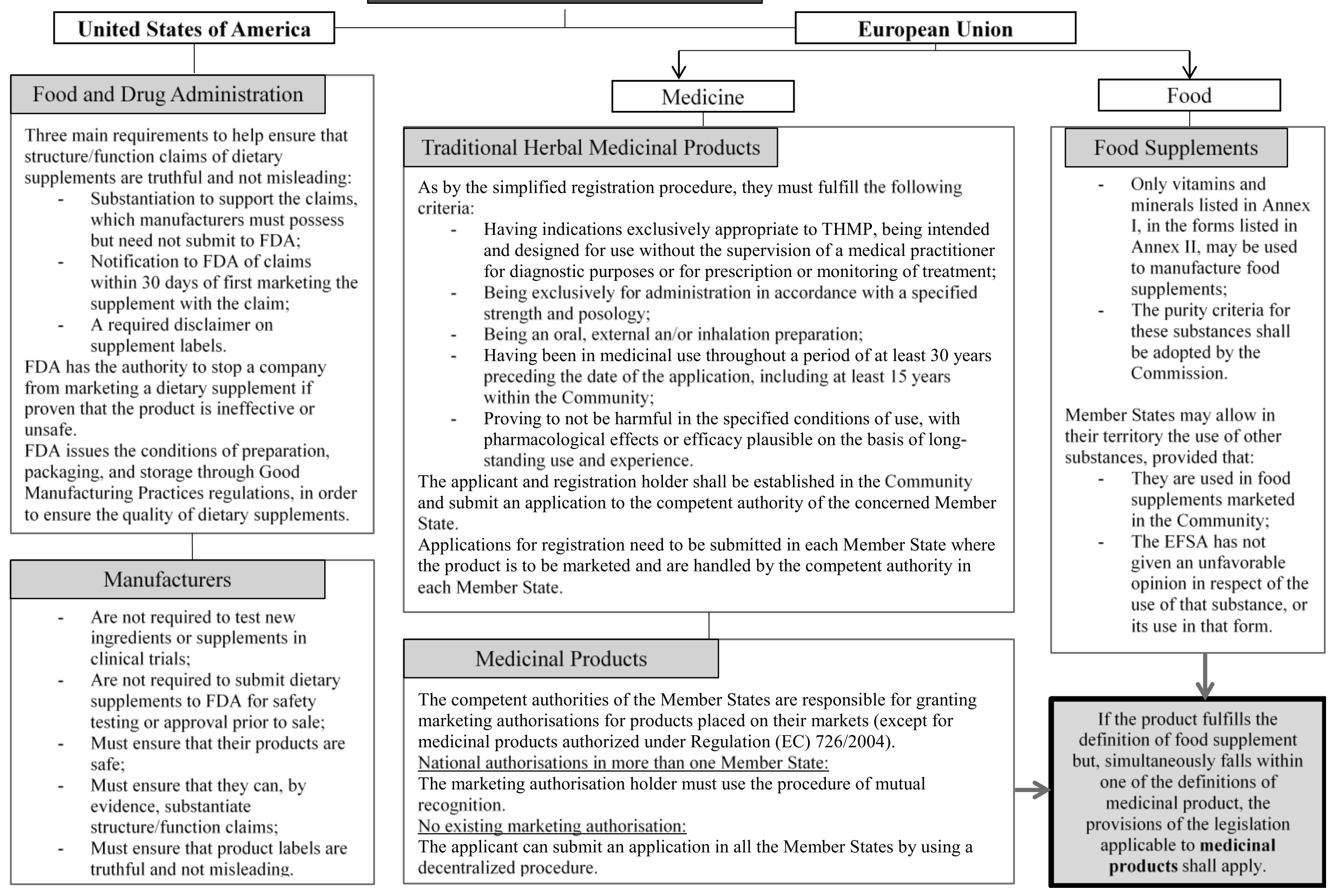

Figure 3. Marketing requirements for dietary supplements in the USA and the EU. 


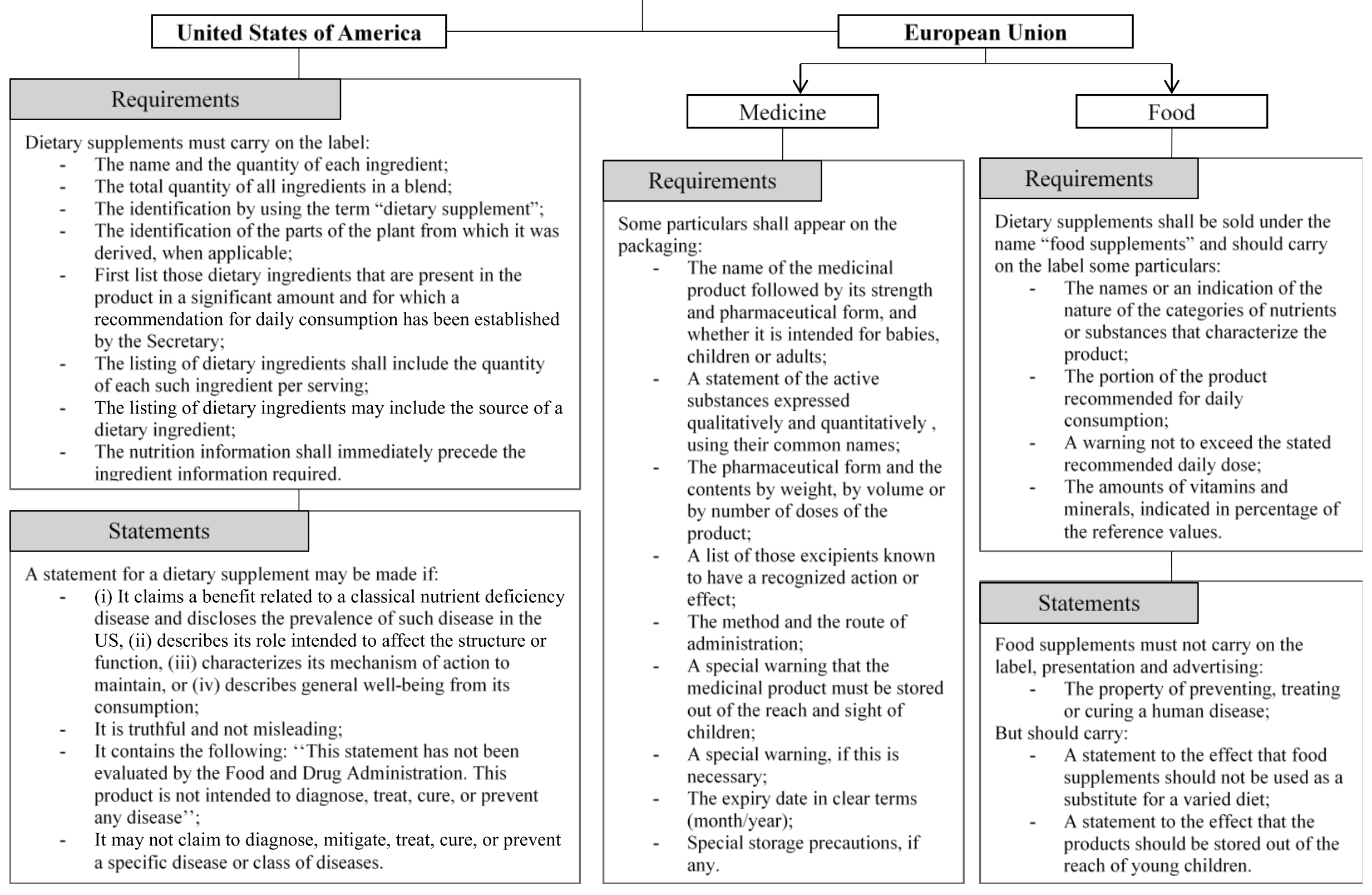

Figure 4. Labelling specifications for dietary supplements in the USA and the EU. 